\title{
Yield strength of structural steel
}

\author{
P.J. Wolert \\ COWI NA, Seattle, USA
}

\author{
A.S. Nowak \\ Auburn University, Auburn, USA
}

\begin{abstract}
Material properties are important in calibration of new generation design codes. The statistical parameters of strength of material often govern in establishing the acceptable safety margin. This paper provides a summary of the available statistical parameters for structural steel produced in the United States including ASTM A709 and ASTM A992, with nominal yield strength $50 \mathrm{ksi}(345 \mathrm{MPa})$ and $70 \mathrm{ksi}(483 \mathrm{MPa})$. The review of cumulative distribution functions (CDF) confirms that the bias factor (ration of mean to nominal) is larger than 1.10 and coefficient of variation for the lower tail of the CDF is less than 0.05.
\end{abstract}

\section{INTRODUCTION}

In the new generation of design codes, safety margin is provided by load and resistance factors. Factored loads are conservatively specified as exceeding the maximum expected value and factored resistance is specified below the low expected value. Values of load and resistance are determined in the reliability-based calibration procedure and acceptability criterion is closeness to the target reliability index (Nowak and Collins 2013). Load and resistance are treated as random variables that are defined by non-dimensional statistical parameters such as bias factor, $\lambda$, and coefficient of variation, $V$. Bias factor is the ratio of mean-to-nominal, and coefficient of variation is the ratio of standard deviation-to-mean value. Structural resistance or load carrying capacity can be considered as a product of three factors that represent the uncertainty in: (1) material properties, (2) dimensions and (3) analytical model. Objective of this paper is to present a summary of statistical analysis of the major property of structural steel, i.e. yield strength.

Material test data was provided by several mills in the United States. The statistical parameters including bias factor and coefficient of variation were determined for two most common steel grades: ASTM A709 steel with nominal yield strength of $50 \mathrm{ksi}(345 \mathrm{MPa})$ and $70 \mathrm{ksi}$ (483 MPa), ASTM A992 with the nominal strength and $50 \mathrm{ksi}(345 \mathrm{MPa})$. ASTM A992 is the most common steel used construction of building frames and bridges. At present, $93 \%$ of steel includes recycled material (AISC 2021). The need for steel with resistance to environmental corrosion drove the development of weathering steel in 1940s such as ASTM A242, A588, and A709. ASTM A709 is the Standard Specification for Structural Steel for Bridges and encompasses carbon, high-strength low-alloy, and quenched and tempered alloy steels used as structural plates in the construction of bridges.

For an easier interpretation of the results, cumulative distribution functions (CDF) of yield strength are plotted on the normal probability paper. Horizontal axis represents the yield strength and vertical axis is the probability of being below the corresponding value of yield. Important characteristic of the normal probability paper is that CDF of any normal random

DOI: $10.1201 / 9781003132134-68$ 
variable is a straight line. The construction and use of the probability paper is presented in textbook (e.g. Nowak and Collins 2013).

\section{STEEL TEST DATA}

\subsection{A992 steel}

The A992 steel test data comes from Bartlett et al. (2001), with a total of 207 flange and web steel coupon specimens. They were obtained from different rolled I-shaped beams provided by three producers, and tested at the University of Western Ontario (UWO) and the University of Minnesota (UM). The resulting CDF's are plotted in Figure 1. In practice, only the lower tail of CDF determines the reliability. For flanges, $\lambda=1.10$ and $V=0.035$ and for webs, $\lambda=$ 1.15 and $V=0.05$.

\subsection{A709-50 steel}

Results of tensile strength tests for A709-50 steel plates were provided by two steel producers. The tests were carried out between 2011 and 2017, about 19,000 samples came from producer A and 2800 from B. The datasets contain yield strength, tensile strength, and elongation but only yield strength data was considered. The test results in the database are for various plates with thicknesses increments of $1 / 16$ inch $(1.6 \mathrm{~mm})$ up to 1 inch $(25 \mathrm{~mm})$, and $1 / 4$ inch $(6 \mathrm{~mm})$ increments above. The resulting CDF's are shown in Figure 2 (Wolert, 2019).

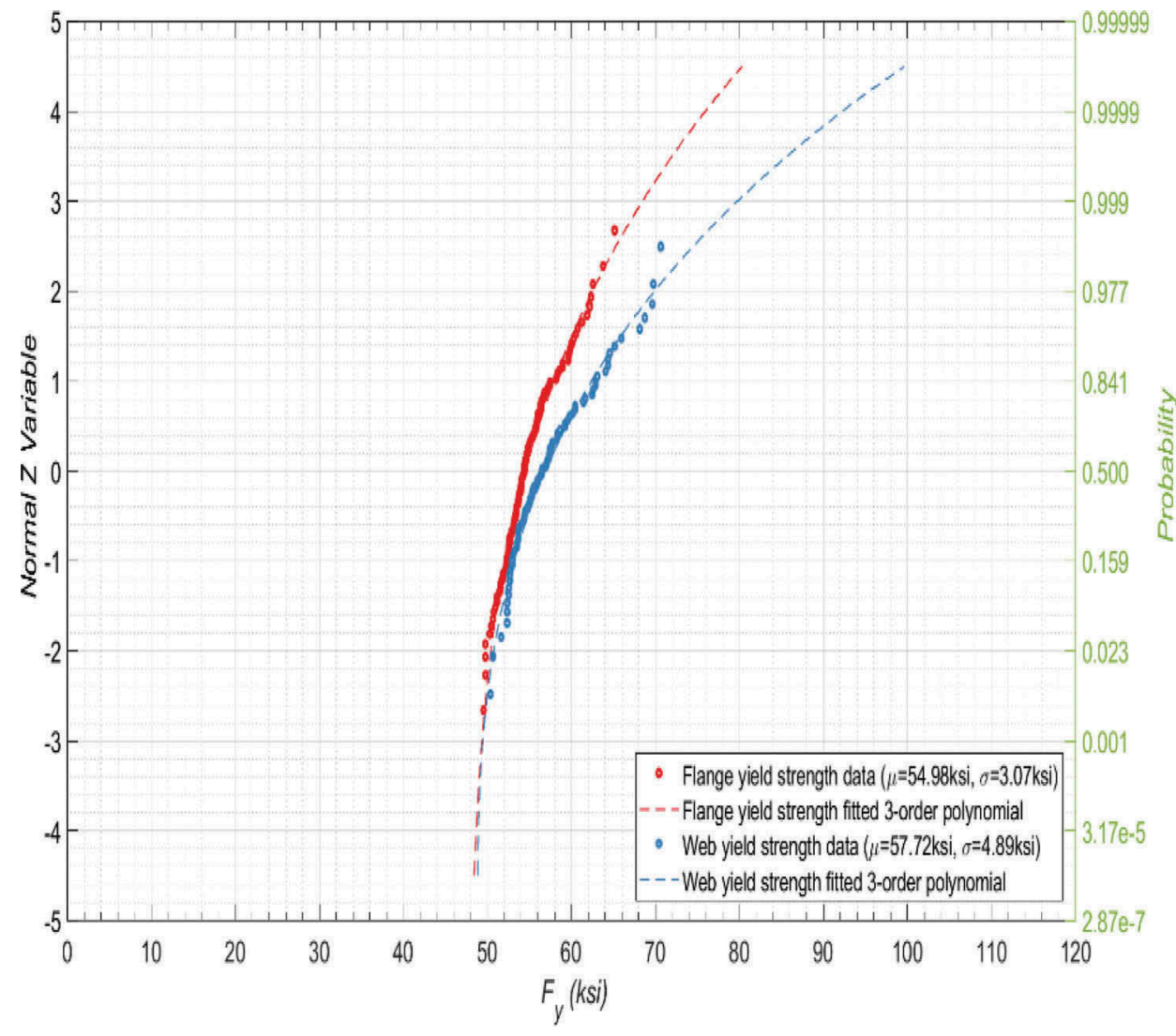

Figure 1. CDFs for the data and fitted polynomials of A992-50 yield strength (345 MPa). 


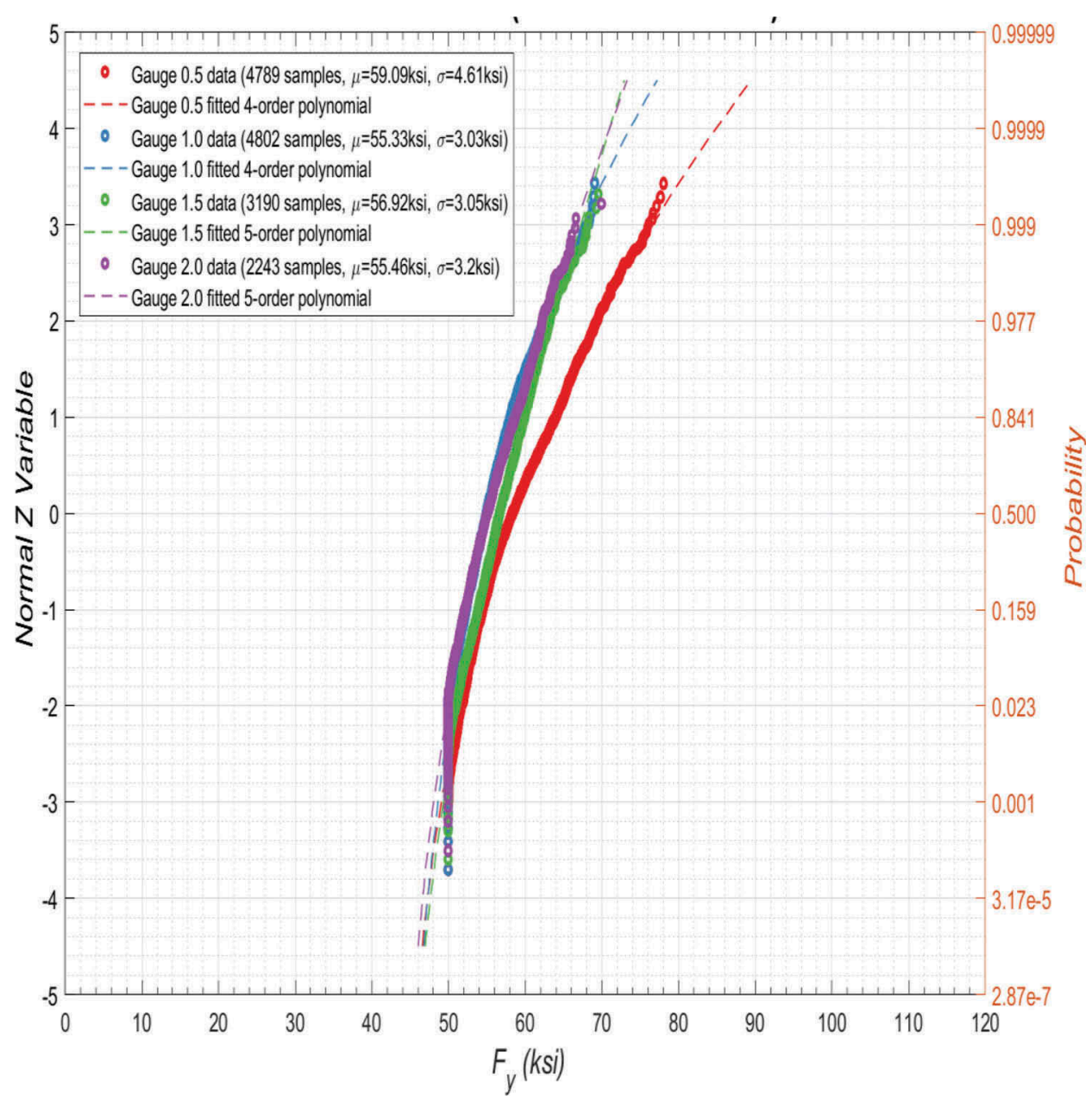

Figure 2. CDFs for the data and fitted polynomials of A709-50 steel from source A (345 MPa). Gauges $0.5-2.0$ inch.

\subsection{A709-50W steel}

Results of tensile strength tests for A709-50W steel plates were provided by two steel producers. The tests were carried out between 2011 and 2017, about 520 samples came from producer A and 3200 from B. The datasets contain yield strength, tensile strength, and elongation but only yield strength data was considered. The test results in the database are for various plates with thicknesses increments of $1 / 16$ inch $(1.6 \mathrm{~mm})$ up to 1 inch $(25 \mathrm{~mm})$, and $1 / 4$ inch $(6 \mathrm{~mm})$ increments above. The resulting CDF's are shown in Figure 3 (Wolert, 2019).

\subsection{A709-HPS50W steel}

Results of tensile strength tests for A709-HPS50W steel plates were provided by two steel producers. The tests were carried out between 2011 and 2017, about 230 samples came from producer A and 160 from B. The datasets contain yield strength, tensile strength, and elongation but only yield strength data was considered. The test results in the database are for various plates with thicknesses increments of $1 / 16$ inch $(1.6 \mathrm{~mm})$ up to 1 inch $(25 \mathrm{~mm})$, and $1 / 4$ inch $(6 \mathrm{~mm})$ increments above. The resulting CDF's are shown in Figure 4 (Wolert, 2019). 


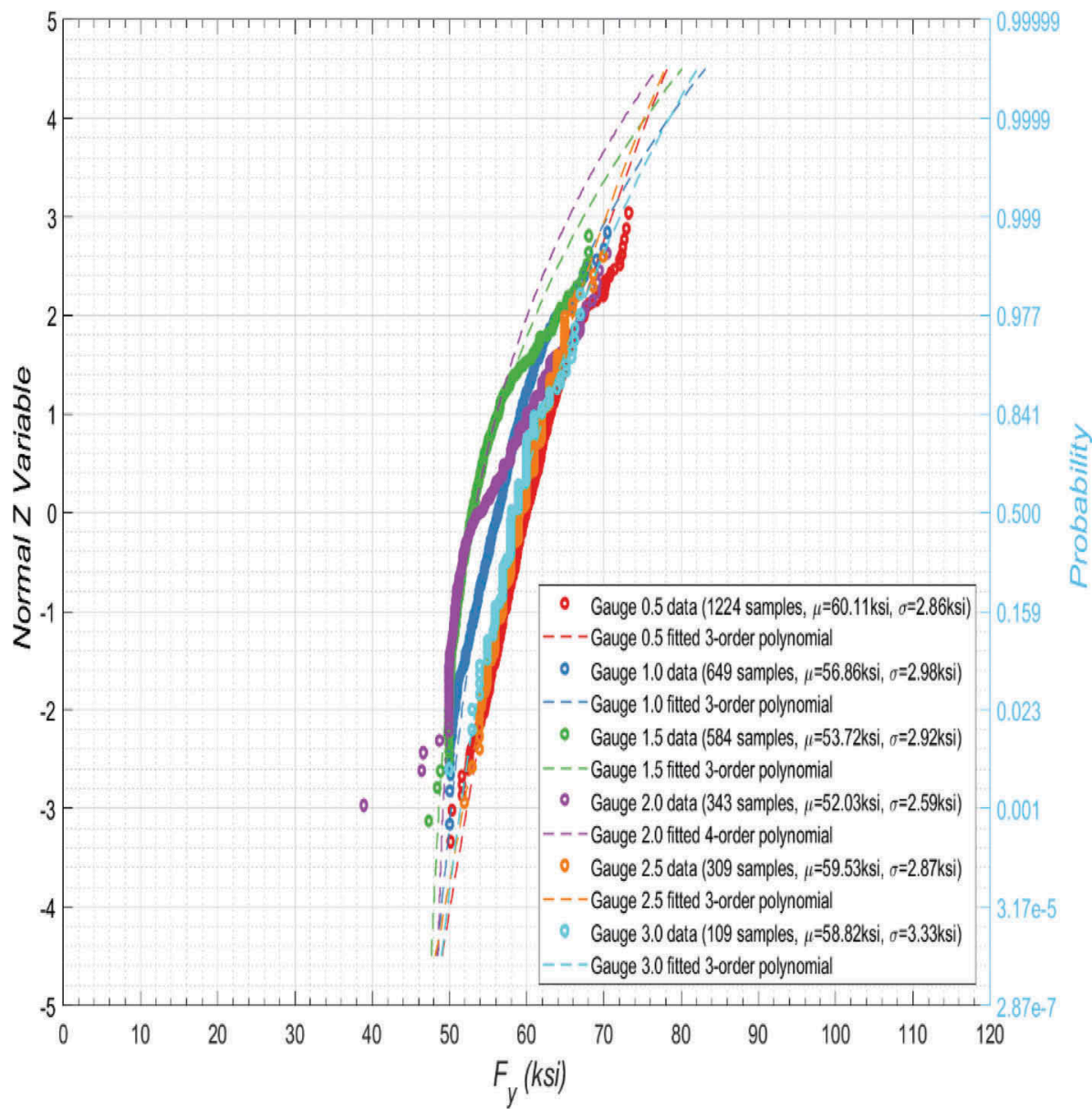

Figure 3. CDFs for the data and fitted polynomials of A709-50W steel from source B (345 MPa). All gauges.

\subsection{A709-HPS70W steel}

Results of tensile strength tests for A709-HPS70W steel plates were provided by two steel producers. The tests were carried out between 2011 and 2017, about 2600 samples came from producer A and 980 from B. The datasets contain yield strength, tensile strength, and elongation but only yield strength data was considered. The test results in the database are for various plates with thicknesses increments of $1 / 16$ inch $(1.6 \mathrm{~mm})$ up to 1 inch $(25 \mathrm{~mm})$, and $1 / 4$ inch $(6 \mathrm{~mm})$ increments above. The resulting CDF's are shown in Figure 5 (Wolert, 2019).

\section{SUMMARY OF STATISTICAL PARAMETERS}

The statistical parameters of yield strength for grade 50 are $\lambda=1.06-1.10$ and $V=0.02-0.03$, grade 50W $\lambda=1.04-1.19$ and $V=0.01-0.03$, grade HPS 50W $\lambda=1.06-1.11$ and $V=0.01-0.03$, grade HPS 70W $\lambda=1.54-1.76$ and $V=0.02-0.06$. The coefficients of variation are for the lower tail of the CDF. 


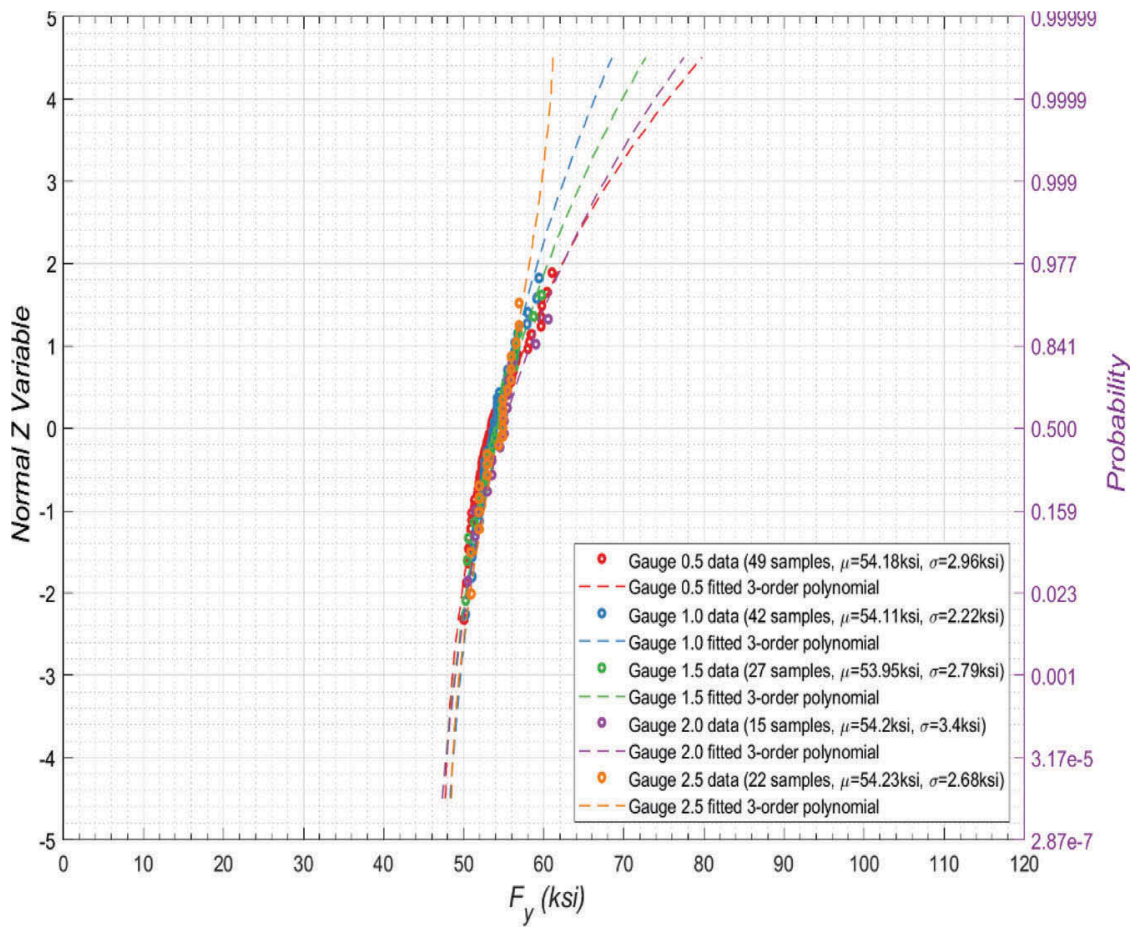

Figure 4. CDFs for the data and fitted polynomials of A709-HPS50W steel from source B (345 MPa). All gauges.

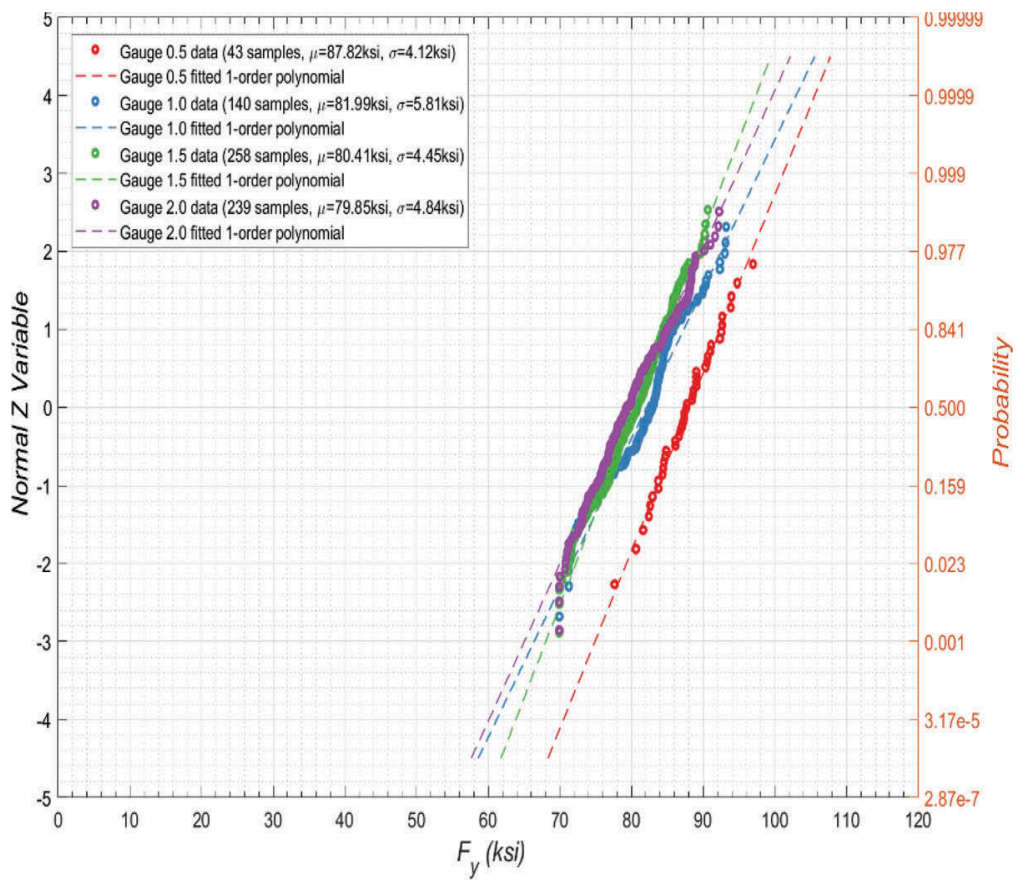

Figure 5. CDFs for the data and fitted polynomials of A709-HPS70W steel from source A (483 MPa). Gauges $0.5-2.0$ inch. 


\section{ACKNOWLEDGEMENTS}

The A709 steel test data was provided by the American Institute for Steel Construction which is gratefully acknowledged.

\section{REFERENCES}

American Institute of Steel Construction, www.aisc.org, accessed on 23 Feb 2021.

Bartlett M. F., Dexter R. J., Graeser M. D., Jelinek J. J., Schmidt B. J. \& Galambos T. V. 2001. Updating Standard Shape Material Properties Database for Design and Reliability. American Institute of Steel Construction.

Nowak, A.S. and Collins, K.R., 2013, Reliability of Structures, CRC Press, New York.

Wolert, P., 2019. Reliability-Based Calibration of the Code for Steel Girder Bridges. PhD Dissertation, Auburn University. 